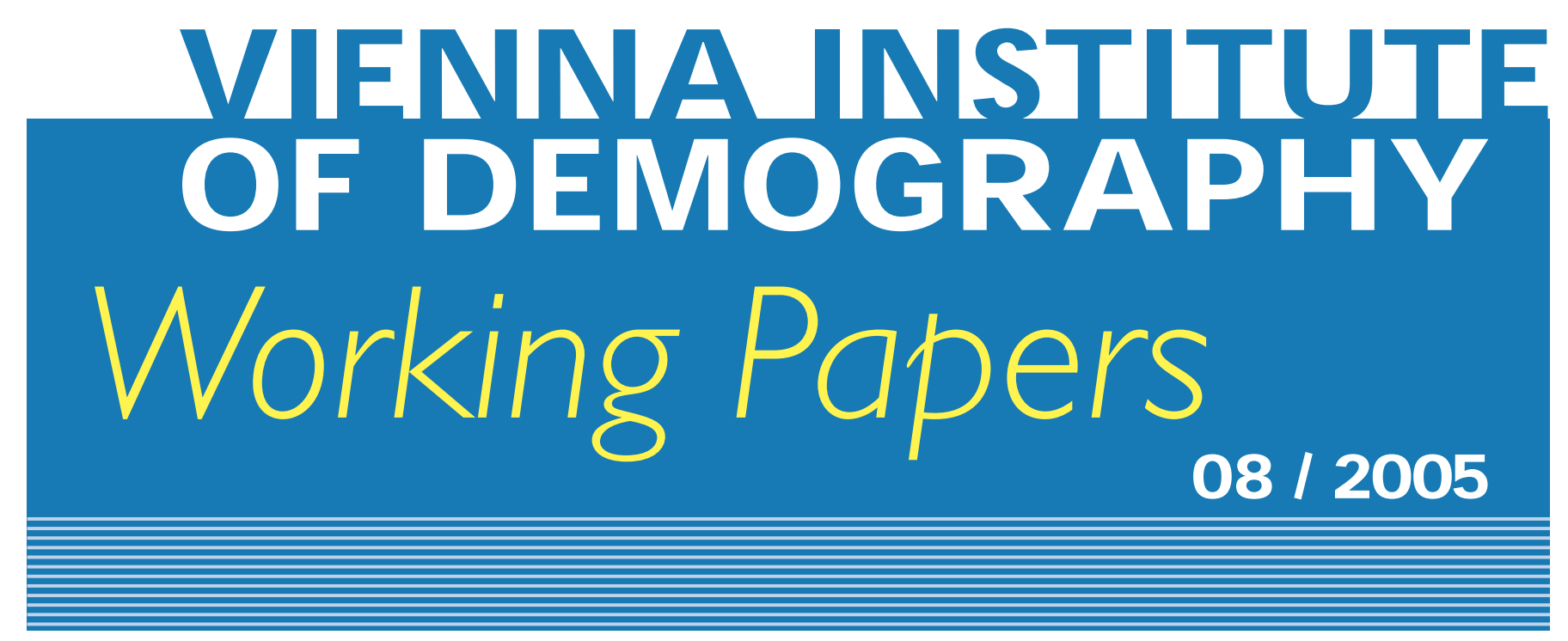

Dimiter Philipov, Zsolt Spéder, and Francesco C. Billari

\title{
N ow or Later? Fertility Intentions in Bulgaria and Hungary and the Impact of Anomie and Social Capital
}

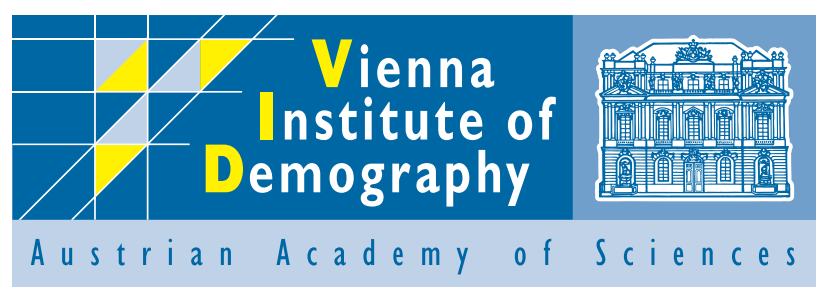

Vienna Institute of D emography A ustrian A cademy of Sciences

Prinz Eugen-Straße 8-10 · A-1040 Vienna · A ustria

E-Mail: vid@ oeaw.ac.at

W ebsite: www.oeaw.ac.at/vid 


\begin{abstract}
:
This paper discusses the construction of fertility intentions in contemporary Bulgaria and Hungary. It presents empirical analyses of four types of fertility intentions: whether to have or not to have a first or a second child and if yes, whether to have this child within the next two years or later. Both countries have recently experienced drastic societal transformations. Based on comparative survey data for women we find that that explanatory factors of fertility intentions differ significantly by order of an intended birth and its timing. We attribute particular emphasis to social anomie and social capital as important factors in shaping fertility intentions and in timing a desired birth. Moreover, economic factors are important determinants in Bulgaria, while ideational and demographic factors are significant in both countries. The findings suggest the necessity of explicitly taking into account birth order and the timing of a desired birth in large-scale demographic surveys and the importance of anomie and social capital in recent fertility choices in Central and Eastern Europe.
\end{abstract}

\title{
Keywords:
}

Fertility intentions, fertility in Bulgaria, fertility in Hungary, social capital, social anomie.

\section{Authors:}

Dimiter Philipov is the Leader of the Research Group on Comparative European Demography, Vienna Institute of Demography, Austrian Academy of Sciences

Zsolt Spéder is the Director of the Demographic Research Institute, Hungarian Central Statistical Office

Francesco C. Billari is Professor, Istituto di Metodi Quantitativi, Università Bocconi and IGIER (Innocenzo Gasparini Institute for Economic Research) 


\title{
Now or Later? Fertility intentions in Bulgaria and Hungary and the impact of anomie and social capital ${ }^{1}$
}

\author{
Dimiter Philipov, Zsolt Spéder, Francesco C. Billari
}

\section{Introduction}

Since the early 1990s, Central and Eastern European (CEE) countries have experienced a drastic fall in fertility. The total fertility ratio, or rate (TFR) dropped down to low levels of around 1.3-1.5. This fall was accompanied by a rapid rise in the mean age at childbearing by order of birth, thus indicating a pronounced trend towards postponing births (Philipov and Kohler 2001, Sobotka 2003a and 2003b, Philipov and Dorbritz 2003). Some demographers have tried to explain these changes by emphasising economic factors, while others have put the accent on ideational change. On the economic side, rapid and intensive economic restructuring has increased the costs of children. Economic uncertainty in times of massive societal transformation had its effect as well. Proponents of the explanation based on ideational change suggest that the overthrow of the totalitarian regimes facilitated the infusion of new values characteristic of democratic societies, which triggered the second demographic transition in CEE countries (see for example United Nations 2002, where cohabitation is discussed; Kotowska 2000, where Poland is considered; and several papers in the volume edited by Kotowska and Jozwiak 2003). Research has also jointly underlined economic and social factors. Kohler et al. (2002), for instance, underlined the importance of higher returns to education on the postponement of births. They also emphasise the significance of changing social norms and describe a mechanism through which these changing standards affect the demographic behaviour of an increasing part of the population.

The above-mentioned research is based on macro-level data. Unfortunately, during the period of societal transformation there were no demographic surveys that were suitable for studying fertility decision-making in more detail. Very little, if anything, is known about individual decisions leading to lower total fertility or to the postponement of desired births in CEE countries, in particular Bulgaria and Hungary.

In this paper we concentrate on fertility intentions as dependent variables. We assume that fertility behaviour is basically the result of a planning process, and that an intention has to be manifest during such planning. We specify different fertility intentions at the individual level, by conducting distinct analyses on the intention to ever have a first or a second child, and on the intention to have that child within the next two years. We use newly available and comparable micro-level survey data for Bulgaria and Hungary. On the side of explanatory

\footnotetext{
${ }^{1}$ This paper is an extended version of a report presented at the 2004 Annual Meeting of the Population Association of America, Boston, Ma., USA, April 1-3.
} 
variables, we emphasise those describing social capital on the one hand, and social anomie on the other, as characteristic of the CEE situation.

We run our analyses on two CEE countries with the primary purpose to test the generality of our findings by way of replication, while we keep only a limited emphasis on comparisons and explanations of differences between the two countries.

Bulgaria and Hungary experienced massive societal transformations and their populations have many common demographic features. In both countries the gross domestic product dropped significantly below its 1989 level during the 1990s. By 2001, it had recovered fully in Hungary, i.e., to 108\% of the 1989 level, while in Bulgaria it was still as low as 73\% (sources of the data cited in this paragraph are internet tables available at the sites of the World Labour Organization, UNESCO, and the World Bank). In the same year the purchasing power of the GDP per capita was twice as high in Hungary (12,000 US dollars versus 6,200 in Bulgaria). Unemployment was considerably higher in Bulgaria, at 19.4 of the labour force as compared to $5.9 \%$ in Hungary. The years of the transition also brought about a substantial rise in the educational enrolment. Thus the number in tertiary education per 10,000 inhabitants in Hungary increased from 99 in 1990 up to 330 in 2000/2001, while in Bulgaria the respective rise was from 216 to 305 .

Total fertility (TFR) in 1989 was slightly below replacement level. During the 1990s it fell drastically: in Bulgaria, the drop was from around 2.0 down to 1.1 in 1997, and in Hungary from 1.8 down to the minimum of 1.3 which was reached in 1999 (Council of Europe 2003). The mean age at childbearing by order of birth increased drastically. For example, the mean age of women at birth of first child in Bulgaria increased from 22.2 in 1990 to 23.9 in 2002, and in Hungary from 23.1 to 25.6. Although order-specific mean ages increased, they remained low in both countries when compared to other European populations. Women have children earlier than in Western Europe, and they usually stop having births earlier. By age 30, some $70-80 \%$ of completed fertility has already been realised, and by age 35 it is close to $100 \%$. Cohorts born around 1965 are expected to reach a level of childlessness of around 10\% in Hungary and 5\% in Bulgaria. The latter level reveals universality of births in this country, while the $10 \%$ in Hungary indicate a low level of voluntary childlessness. The low levels of overall fertility and of childlessness indicate that a sizeable number of births are of first order. In 2002, 57\% of all births in Bulgaria were first births, and in Hungary this proportion was $45 \%$; correspondingly, the percentage of second births relative to first births was $55 \%$ in Bulgaria and 70\% in Hungary (Council of Europe 2003).

The remainder of this paper is structured as follows: Section 2 discusses the theoretical background that guides our choice of dependent and explanatory variables. Along with the familiar discussion on the economic situation of individual women and their value orientations, we argue that it is crucial to incorporate the effects of social capital and anomie. The next three sections discuss data and methods, description of variables, and model results. The final section presents a general discussion. 


\section{Theoretical background}

\section{Intentions and fertility}

Our subsequent analyses concentrate on fertility intentions as the key set of dependent variables. Consistently with the social-psychological literature, we consider fertility intentions as the main proximate determinants in the actual decision to have a child in contemporary societies. A major reference on the link between intentions and behaviour is the theory of planned behaviour (e.g., Ajzen 1991). According to this theory intentions are formed by the composite effect of attitudes towards the behaviour in question, in our case a first or a second birth, by subjective norms regarding the behaviour, and perceived behavioural control. Thus formed, intentions can be seen as "proximate determinants" of behaviour. Hence factors that have an impact on intentions have an impact on behaviour as well. The inverse is not necessarily true, i.e. there are intermediate factors between intentions and actual behaviour. Unintended births and failure to conceive serve as examples. The latter need to be considered for a study of births; however in this paper we focus only on intentions.

Miller and Pasta provide an overview of the use of fertility intentions in explanatory models of fertility behaviour (1994); they also show the importance of explicitly considering intentions as being connected to a specific timing (1995).

A general scepticism seems to prevail about the use of fertility intentions as predictors of fertility, mostly because a certain proportion of fertility intentions remain unrealised (e.g., Quesnel-Vallée and Morgan 2003). This result is consistent with the assumption that both intentions and childbearing are the outcome of a decision process within a context of changing constraints. Inevitably, some time elapses between the intention to have a child and its realisation; during this period some factors underlying the construction of a "positive" intention may change, and as a result individuals may change their intention, by either rejecting the birth or postponing it. By analogy, negative intentions can later turn positive. Morgan (2003) refers to these changes as "revisions" of intentions. However, Williams et al. (1999), using U.S. data, showed that intentions concerning a specific time interval are indeed good predictors of individual behaviour: in their case study, on the example of "negative" intentions, only $10 \%$ of the women who declared they did not intend to have a child within a three-year interval actually did have one during that period.

Fertility intentions may happen to be optimistic, particularly so among young adults who underestimate the significance of restrictive factors on childbearing, or overestimate their ability to control them (Weinstein 1980). However, these results in our opinion cannot be directly transferred to the case of Bulgaria and Hungary during the transition. As described below, the dynamics and strength of the transition caused a considerable increase in anomie, disorientation and uncertainty in both countries. One might even suspect that optimism was replaced by pessimism. A longitudinal survey of marriages contracted in 1990 and 1991 in 
Hungary is informative on this issue, showing that the 1991 family plans for the intended number of children turned realistic ten years later (Kamarás and Szukics 2003).

We discuss two components of fertility intentions. One relates to the intention to ever have a child ("ever" or "never"), and the other is associated with the timing of an intended birth: within the next two years or later ("now" or "later"). Both types of intentions are further separated by birth order for the following reasons.

Where very low fertility prevails most people have either no children or one, sometimes two and rarely three or more children. This is the case for both Bulgaria and Hungary. We focus here on fertility intentions related to the first and separately to the second child. There are clear indicators that fertility intentions for having a first and a second child should be analysed separately. Having a first child means "to become a parent", an irreversible transition (Hobcraft and Kiernan 1995). Moreover, the timing of a first child is closely connected to completion of education, working career, entry into a union.

Since fertility intentions are the main factor for the corresponding behaviour and based on certain observations about fertility trends briefly mentioned in the introduction, we expect a priori that intended childlessness will be about as low as observed childlessness, and intentions for having a second child will be considerably lower, as is the level of births of a second order. This conspicuous difference calls for an order-specific theoretical approach in the search of explanatory factors.

\section{Economic factors and education}

In the classic comparative static approach (Becker 1990, also Chapter 6 in Ermisch 2003), direct and indirect income effects have an impact on the choice of a lifetime number of children in one's utility function, while in a dynamic setting the choice for having a child is restricted within a period of time. Dynamic microeconomic fertility models study a sequence of periods in which individuals make their choices to have a child or not (Arroyo and Zhang 1997, and Hotz et al. 1997 provide reviews on this topic). Thus they include the timing of a birth. Gustafsson (2001) reviews research that provides analyses of timing, or postponement, of maternity. According to Gustafsson, postponement is linked to the lower costs of a later birth (costs accumulated through lifetime work), and the most important factors influencing postponement concern the woman's career costs. The man's income figures among the significant factors as well.

So far, no similar analysis has been carried out for countries in transition such as Bulgaria and Hungary. A direct inference from results concerning other countries is undesirable, because of the drastic differences between the economic and social situations. We therefore concentrate on a descriptive discussion of the impact of economic factors on fertility intentions and births.

One of the most characteristic social outcomes of the transition period in Bulgaria and Hungary was the severe rise in income inequality. For a large number of people the personal 
income dropped close to, and sometimes below, subsistence level. However, low personal income could be compensated within the family by a larger income of the spouse. Moreover, in both countries there is a tradition of extended households, where the young family resides together with the parents of one of the spouses. Intergenerational transfers are significant by tradition as well. All these considerations suggest that household income could be of considerable significance for the construction of intentions or decisions to have a child.

Women's unemployment can have different effects on childbearing. On the one hand, opportunity costs are low and as long as the income of the spouse (or the household income) is sufficient, a couple may opt to reschedule the birth of a planned child. On the other hand, unemployed women may long to find work, either in order to make a contribution to the insufficient household income, or to search for an opportunity for self-realisation through work. In these cases unemployed women may prefer to postpone a birth. In both countries, female labour force participation rates were and are still high and it is likely for a woman to work rather than stay at home as a housewife. From this descriptive point of view the second effect can be regarded as more likely.

The individual experience of economic uncertainty is a key characteristic of the transition period. The high levels of uncertainty are the result of the dynamics of the transition towards a market economy. In general, a decision-maker is likely to postpone crucial life decisions such as on having a child when uncertainty prevails. This was one of the key factors that contributed to the drastic fertility drop in East Germany during the first half of the 1990s (Ranjan 1999; Bhaumik 2002). Under conditions of economic uncertainty a person's income and employment become insecure, and this may decrease their significance in shaping fertility intentions.

The newly formed private sector in the economies of Bulgaria and Hungary remains unstable, although its share of the GDP exceeds 50\% in both countries. In particular, jobs in the private sector are more insecure as compared to those in the state sector. Hence the type of ownership of the place of work can indirectly measure economic uncertainty of working persons: state or private.

Although we discuss micro-level issues it is instructive to describe the impact of macro-level changes in the labour market and in the educational system on fertility. Spéder (2002) presents an analysis for Hungary. The radical restructuring of the labour market in terms of demand for new professions and skills that were irrelevant to a planned economy, as well as the abolishment of the planned educational system, brought about the rise in educational enrolment particularly in the tertiary sector (see the remarks in the introduction). In the life course, usually, the completion of education precedes parenthood. In cases where a birth precedes the completion of education, this can be a reason for dropping out of education (Billari and Philipov 2004, find the same interrelation between educational enrolment and union formation in CEE countries). Hence, the increase in the number of students in the tertiary educational sector may explain a significant part of the decrease in fertility and the increase in its mean age. In addition, some students need to work in order to support their 
study. This leads to a prolongation of education, resulting in an additional postponement of births. Education has an effect on fertility also beyond the timing of life-course events, being the main constituent of human capital. In the context of our study we expect that longer education is associated with a postponement of births. This relation can be particularly outlined for the first birth that marks the beginning of motherhood.

\section{Ideational change}

Ideational change is a main motor behind demographic trends according to the proponents of the idea of Second Demographic Transition (SDT). Lesthaeghe and Surkyn (2002) describe changes in the value systems towards a rise in post-modern values with three main components: (i) accentuation of individual autonomy; (ii) rejection of all forms of institutional control and authority; (iii) rise of expressive values connected to selfactualisation, self-fulfilment, and quest for recognition. The rise of post-modern values oriented towards the self is accompanied by a relative decline in values related to family formation and dissolution, including childbearing. Discussions for CEE countries can be found, among others, in Kotowska and Jozwiak (2003) and United Nations (2002; see also Lesthaeghe and Surkyn 2002). The application of this explanatory approach rests on the understanding that the overthrow of the totalitarian regime facilitated the infusion of new values characteristic for modern democratic societies. Shifts in values and attitudes have thus lead to a drop in total fertility, and in a postponement of fertility, analogously to what has been observed in Western Europe. The major difference is that in CEE countries the changes have occurred much faster.

Some key post-modern value orientations that are discussed in the context of the SDT could be observed in Bulgaria and Hungary even before the start of the transition, for example increased female autonomy and secularisation. Female autonomy had risen as a result of the high female labour force participation forced by the planning systems, as well as by the necessity of a higher family income in conditions of wage levelling. Other key post-modern values, such as the rejection of all forms of institutional control and authority (except for the decreased influence of the church institutions as a result of secularisation) or increased selfexpression, could hardly emerge before the start of the transition because of the very nature of totalitarian regimes.

\section{Social anomie}

The societal transformation that started in 1990 was, and is, a fundamental change in the entire institutional, political, economic, social, and cultural setting. The replacement of the totalitarian regime by a democratic one brought about the necessity of changing institutions and adopting a new system of legal acts, which needed more than one decade to be implemented. At the same time the transformation encompassed a sudden breakdown of old norms and values and the emergence of new orientations. However, the rise and stabilisation of a new value system needs time. The period between the old and the new societal systems is 
one of normlessness or anomie. Spéder et al. (2002) and Genov (1998) for example provide relevant discussion in the case of Hungary and Bulgaria.

Anomie can be considered from two main perspectives, due to Durkheim and Merton. Following a Durkheimian perspective (Durkheim 1964, 1966), under the state of anomie the prescriptive power of norms is weakened or lost, and people lose orientation in making plans about life events. Disorientation in life and uncertainty are the result. As a consequence some people are subject to deteriorations in their mental status and in more extreme cases they may become depressed and start questioning the meaning of life. Merton (1966) considers anomie in a broader framework of cultural structures and social systems. Individuals set their goals and desires within the cultural structure; norms prescribing the legitimate means for meeting these goals exist also in the cultural structure, while the social system contains the institutionalised means. The lack of harmony between goal-attainment and the relevant means, or more broadly the disjunction between the cultural and the social systems, results in an anomic society. The disharmony between goals and means at the macro-level of the society causes a rise in negligence of norms and distrust in institutions at the micro-level. As a result people who neglect norms may turn to deviant behaviour, while people who set themselves certain goals in agreement with their cultural environment may be unable to reach these goals because of failures in the social system. The latter group fails to adapt to the social environment and feels alienated. It is important to note that anomie arises in a rapidly changing society where the transformations also lead to rapid increases in prosperity. As a result of anomie, whether in the Durkheimian or Mertonian perspective, people may feel a lack of orientation, uncertainty, powerlessness, loneliness, and psychological discomfort.

Anomie in CEE countries has been the subject of numerous studies. Arts, Hermkens, and Van Wijck (1995) viewed disorderliness in these countries in the light of the theory of (social) anomie. Genov (1998) studied the impact of anomie on quality of life in Bulgaria. Using survey results, he found high levels of reported uncertainty, anxiety and fears. He classified the latter as indicating an anomic situation. Anomie has frequently been studied in Hungary before and after the start of the transition (Andorka 1994). It is argued that anomie has increased during the first years of the transformation; it has exercised a sizeable impact on quality of life (Kopp et. al. 1999, Spéder et al. 1999, Spéder et al. 2002). Individuals may experience different degrees of anomie (Rabušic and Mareš 1996, in their study of social anomie in the Czech Republic).

Under the prevalence of anomie, decision-making becomes fuzzy. It can be expected that crucial life-course events such as the birth of a child will be postponed if not at all rejected. A prominent indication about this inference is provided by the scale for measurement of anomie in surveys, suggested by Srole (1956), where one of the questions is "Do you agree with the statement: It is hardly fair to bring children into this world with the way things look for the future?" I.e., in Srole's scale anomie is explicitly connected to the lack of desire for having children. 
The impact of anomie on fertility decisions has not been studied in detail although Philipov (2003) argued its significance for CEE countries. The topic of anomie and the resulting disorientation, uncertainty and psychological discomfort can be considered from the perspective of ideational change. Anomie is linked directly to the second of the above three components of ideational change proposed by Lesthaeghe and Surkyn (2002). Major forms of institutional control, such as those related to the legal system and social norms, became ineffective during the social transformation in the CEE countries. Achievement of individual autonomy appears as an outcome of the weakened and disappearing regulatory power of institutions. Some people may cope well with autonomous decision-making regarding their own life course and may expand their value orientation towards self-expression and selffulfilment. Others may miss the prescriptive power of institutions and remain unable to take autonomous decisions; they experience uncertainty and disorientation. It has become customary among social scientists in CEE countries to refer to these groups of people as "winners" and "losers" of the societal transformation (Habich and Spéder, 1998).

\section{Social capital}

The dynamics of the transition period make it more difficult for the state and other relevant institutions to provide effective support for people in need. People may therefore rely to a higher extent on additional support they might get from relatives, friends, neighbours, or colleagues. This kind of support refers to social network-based social capital. It is defined as the availability of resources in one's social network. The more resources can be raised, the higher the support and therefore the better the economic situation of the person. Social capital is not paid; it is usually provided in the form of help from others. The help can have any form: loan of money, work, care for children, supply of important information. Inversely, the person provides support to those members of his personal social network who are in need of help. Thus social capital relates to trust and reciprocity. In general, social capital may ease the economic situation and decrease uncertainty, but its effect comes through social relations and not through economic action; therefore its effect on fertility does not relate directly to economic theory. Philipov and Shkolnikov (2001) suggested first this theoretical specification; Philipov (2003) discusses the impact of social capital on fertility intentions in Bulgaria and Russia; Buehler and Philipov (2005) provide a rigorous theoretical discussion.

The topic of social capital is not new to the study of fertility decision-making. In the theoretical framework suggested by Schoen et al. (1997) increasing social capital was a motivation for parenthood. They found that fertility intentions in the USA were higher among people who perceived that their social capital would increase after childbirth. Astone et al. (1999) give a detailed theoretical discussion. In our context we suggest a different link: people with higher social capital may feel more secure and hence may be more likely to intend to have a child. Both viewpoints do not contradict each other; on the contrary, they are complementary. 


\section{Data and methods}

We use data from two recent surveys. The survey in Bulgaria was carried out in 2002 with the purpose of studying family formation and childbearing. The sample size included 10,003 men and women aged 18-34. In this analysis we use a sub-sample of women aged 1834 who have less than two children. The survey in Hungary was carried out in 2001 to study family formation, childbearing, and preparation for retirement. The sample consisted of around 15,000 men and women aged 18-75. We used a sub-sample similar to the Bulgarian one. We focus on intended births of first and second order only. As mentioned in the introduction, fertility at these orders is nearly completed by age 35 in both countries. Respondents who declared not to be fecund are not included in the analysis. The sizes of the sub-samples after cleaning are given in the Appendix.

Although the two surveys are thematically similar they were organised independently and the data they provide needed some post-harmonisation. As a result, some of the variables we use are not fully comparable. This deficiency of post-harmonised data is countered by their advantage, in that they "...allow researchers to replicate analyses in different countries and test the generality of findings" (Gauthier 2002, p. 9).

In both surveys intentions are addressed with two key questions, specified in each survey as follows (specifications for pregnant women and on the order of births are skipped here). In the Bulgarian survey the first question was "Do you intend to have a (another) child during the next two years?" Respondents who answered in the negative were additionally asked: "Do you intend to ever have any (more) children?" In the Hungarian survey the first question was: "Would you like to have any (more) children?" and the second one was "At what age would you like to have your (next) child?".

We have two dependent variables: the first measures the intention to have or not to have a/another child; the second measures the timing of an intended birth, whether within two years or later. Evidently, the second intention depends on a positive statement on the first one, and women who intend not to have any more children are selected out of the whole sample.

The modelling strategy should in principle reflect this selection. For this purpose we used a probit model with sample selection (Van de Venn and Van Pragg 1981). It consists of two probit equations: the first one specifies intentions to have or not to have a/another child, and the second one, known as the selection equation, specifies intentions to have the child in two years or later. A correlation coefficient between the "residual" component of the two equations, $\rho$, provides an idea on whether selection due to unobserved variables plays a role. This sample selection model is very sensitive to the inclusion of independent variables. Since theory does not provide help in choosing variables that are expected to have an effect on intentions as specified here, we were guided by our empirical trials. We first studied each of the equations independently, disregarding sample selection. Then we kept the statistically significant variables for the exact model specification with selection. The estimations were run 
using STATA ${ }^{\circledR}$ (Statacorp 2003). The results indicated that the correlation between the error terms in the two equations, $\rho$, is statistically not different from zero. That is, given the covariates we included, sample selection does not have an effect on the statistical significance of the coefficients of the equations. We also explored changes in the set of independent variables and found that the addition of those that were statistically insignificant when running the equations independently, did not change the significance of $\rho$.

The conclusion is that the use of two independent equations, one for the "ever" and one for the "now" intentions, will not give biased estimates of the coefficients (Dharmalingam and Morgan 2004, use the same approach). We opted for a logit specification of our models, as they are easier to interpret in terms of odds ratios.

\section{Variables and descriptive data}

The dependent variables were defined in the previous section. We describe the explanatory variables (connected to the theoretical background outlined in Section 2) in five groups: demographic, economic factors and education, related to ideational factors, to anomie, and to social capital.

Demographic variables. This group includes:

- Age. The age groups are 18 to 24, 25 to 29, and 30 to 34 completed years of age.

- Marital status. It includes three states: not living with a partner, married, and cohabiting.

- Number of siblings (none, one, two or more). This variable informs about the size of the family where the respondent grew up.

- Age of first child. This variable is continuous and is exact to the month of birth (its replacement by an ordered categorical variable with several intervals did not improve the results).

Economic factors and education. They include the following four variables:

- Living conditions. In the Hungarian survey the question was formulated as "How satisfied are you with your apartment (or house)?" The answer was a choice in a scale from 0 (not satisfied at all) to 10 (fully satisfied). In the Bulgarian survey the question was the same, and the answer was a choice among 4 categories. The Hungarian variable was used as a continuous one, and the Bulgarian was transformed to a dichotomous variable. 
- Education. Three levels according to the attained educational degree: below secondary, secondary completed (approx. 12 years in school, usually completed at age 18-19), and higher than secondary.

- Occupational status. The number of possible states for women with no children is 4: (1) neither works nor studies; (2) studies, does not work; (3) works in a state company; (4) works in a private or a mixed company. The first category is divided into two for the women with one child by delineating those who are on maternal leave into a separate, fifth category. In Hungary "maternal leave" was defined for women who did not work at the time of survey, while in Bulgaria it referred to women who did not work during the last three months. Hence the proportion of this group is lower in Bulgaria.

- Equivalent income in the household. It is measured as follows: the overall household income is divided by the number of household members raised to the power of 0.73 , to take account of the distribution of consumption in the household. The results are grouped in four categories based on quartiles.

Household income drops considerably for households where women have one child, compared to those with no children. The average monthly equivalent income per household member with childless female respondents in Bulgaria was 154 leva (approx. 2 leva= 1 euro), while for women with one child it was 117 leva, i.e., a drop by nearly one third. In Hungary the equivalent income in households where the female respondent has no children is around 60 thousand forints (approx. 250 forints $=1$ euro), and where the respondent has one child it is 42 thousand forints: again a decrease of nearly 33 per cent.

We do not use personal income in this study. In Bulgaria personal income was reported in intervals, and $51 \%$ of all respondents indicated their income in one and the same interval (from 100 to 200 leva, app. 50 to 100 euro; the minimal wage at the time was 100 leva). Less than 5\% reported personal income higher than 350 leva. So the income reported agrees with the overall observation that a large part of the population has a low income and only a few have a high one. The lack of variation made the variable inconvenient for our study. The situation in Hungary is not much different.

Variables related to ideational factors. Both surveys give extensive opportunities for experimenting with numerous variables potentially related to ideational change. Beside religiosity, we specifically selected variables that are specially related to childbearing. We thus use three variables.

- Religiosity. The question concerning religiosity in the Bulgarian survey was formulated as: "Independently of whether you go to church or not, can you say that you are..." with two possible answers: "... a religious person" or ".. not a religious person". In the Hungarian survey the respondent was asked to select one of the following four answers: (1) "I am religious, I follow the teaching of the church"; (2) "I am religious in my own way"; (3) "I 
can't say whether I am a religious person"; (4) "I am not a religious person". The first two categories were aggregated in a single one, as were the 3rd and the 4th.

A question on religious affiliation was asked in Bulgaria. However, in this country affiliation to Orthodox (some 90 percent of the population) is associated by and large with cultural identity, i.e. non-religious people will feel themselves as belonging to the Bulgarian Orthodox. Religious practice was measured in the Bulgarian survey by the frequency of attendance of religious ceremonies. It was found very rare, and highly correlated with the question used in our analyses. Religious affiliation and attendance of ceremonies were not asked in the Hungarian survey.

The questions we use measure self-assessed religiosity that goes beyond religious affiliation. Davie (1993) discussed "believing without belonging"; Stark et al. (2005) found that spirituality and unchurched religion is on the rapid rise in Sweden, preponderant in Japan, and most of those in the USA who do not have religious preferences are quite religious. These findings support the subjective measurement of religiosity considered here.

Huber (2003) has found that self-assessed religiosity is highly correlated with a detailed 5-item scale of religiousness. The use of this single variable is therefore convenient where religiosity in general is considered (Huber 2003, p. 255).

- Parental obligations to children. Respondents were asked whether they agree or disagree with a statement, formulated in the Hungarian survey as follows: "Parents do have obligations to their children but they do not have to sacrifice their aims for them", and the choice was between two categories: "agree" and "disagree". To respondents who were unable to make a choice, an additional alternative was given: "uncertain". In the Bulgarian survey the formulation of the question was similar ("Parents have a life of their own and should not be asked to sacrifice their own well-being for the sake of their children.") and the number of categories was 5: "fully agree", "agree", "neither agree nor disagree", "disagree", and "fully disagree"; for the analyses the 5 categories were collapsed to 3.

- Work versus having a child. In the Hungarian survey the respondents were asked whether they agree with the statement: "Women with a good profession and a good job are right to consider work more important than having more children", and the answers were like in the previous case. In the Bulgarian survey the question we used was formulated differently: "If you have a child during the next two years, independently of whether you want one, would this child decrease your opportunities for professional career and/or higher education?" the answer being one among the five categories listed above. Again the categories were collapsed from 5 to 3 .

Apparently this variable can have different interpretations in the two countries. The Hungarian one is impersonal and reflects an attitude to a modern value associated with the desire for personal economic autonomy and self-fulfilment, while the Bulgarian one describes the respondent's opinion on whether childrearing would impede her personal working career. 
The Bulgarian variable can be ambiguous: it may describe either an ideational attitude, or reflect an economic/social situation of the respondent. A test for the latter was done using the following question: "If you were to go pregnant how likely is it that you would lose your job?" The correlation between the two variables is 0.15 , when working respondents only are considered. We ran the models specified with inclusions of both variables and/or their interaction, thus controlling for the effect of losing a job. The statistical significance of "work versus having a child" remained persistent, except that the level of significance changed. This made us conclude that the variable reflects ideational views, and the final model specifications did not include the control variable.

\section{Variables related to anomie}

As discussed in Section 2, anomie may cause an increase in disorientation, uncertainty, alienation, and worsen one's psychological well-being. Both surveys include several questions related to these matters. The questions represent batteries frequently used for the study of anomie in Hungary for more than a decade (Spéder et al. 1999). The batteries provide a direct measurement of anomie and alienation along five dimensions, briefly stated as: violating norms and rules; powerlessness; lack of orientation; alienation from work; loneliness. We found that violating norms and alienation from work have no effect on the formulation of fertility intentions and skipped these two dimensions. For the purposes of the regression models we needed common factors that would reduce the number of variables.

- Psychological well-being. This was measured using two variables and reflects the "loneliness" dimension of anomie. In the Bulgarian survey they were formulated as: "During the past month have you ever felt very lonely or remote from other people?" and "During the past month have you ever felt depressed or very unhappy?" In the Hungarian survey the respondents were asked to assess the relevance to their own case of the following formulations: "I often feel lonely", and "I feel that intimacy and warmth are missing from my life". Each pair of variables was factorised and the common factor was used in the models.

- Disorientation. Respondents were asked to agree or disagree with the following statements (as phrased in the Hungarian survey): (1) "I have no influence over my everyday affairs"; (2) "Life is so complicated nowadays that most of the time I don't know what to do"; (3) "No one cares what happens to other people". The answer in the Hungarian questionnaire was one among four categories: fully agree, agree, disagree, and fully disagree. In the Bulgarian survey the categories were five: fully agree, agree, neither agree nor disagree, disagree, fully disagree. The three variables were factorised and the common factor we call "disorientation". It reflects the dimensions "powerlessness" and "disorientation" of anomie.

\section{Variables related to social capital.}

We use a simple and effective operationalisation of social capital based on exchange of help. It is suggested by Philipov and Shkolnikov (2001; see Philipov 2003), while Buehler and Philipov (2005) provide a detailed discussion. 
We use two basic variables named "help received" and "help given". "Help received" is derived in the Bulgarian survey from two questions: "During the last two years, how many people gave you substantial, important help or support?" and "If you need substantial help and support, how many people can you ask for this?" The first question is designed to inform whether the respondent has actually used any resources from her social network. The second question informs whether such resources would be available, were they to become necessary, and it was asked only to respondents who answered negatively to the previous question. The answer to each of these questions is in terms of number of people. The variable "help received" combines the answers to both questions (see also Buehler and Philipov, 2005).

In the Hungarian survey this variable was derived from three questions: "In the past year did you receive regular assistance in the form of money from a person not living in your household (parents, children, other relatives, someone not related)?", "Do you receive any regular help nowadays with household work from a person not living in your household (parents, children, other relatives, someone not related)?", and "Do you regularly receive food (e.g. vegetables, meat) from someone not living in your household (parents, children, other relative, someone not related?" The answer in the Hungarian survey was "yes/no", and "if yes, from a parent, a child, other relative, other person". The three questions contain altogether 12 sub-questions specifying the type or amount of help. We assembled the answers "yes/no" to the 12 sub-questions to get the variable "help received". Thus the variable denotes the number of answers with "yes" that can vary from 1 to 12 ; the value "zero" corresponds to the situation where no help was received.

The variable "help given" was constructed using similar questions in each country, with the direction of help being reversed. The measurement of "help given" informs on the reciprocity in exchange of help within the respondent's social network.

The two variables "help given" and "help received" were highly correlated; their separate effect in the models was difficult to distinguish, and therefore they were factored into one variable named "exchange of help". Increasing values of this variable correspond to an increase in the exchange of help. Factorisation has a theoretical basis too. We define social capital with respect to impersonal exchange of help. This is what the factorised variable reflects.

There are several important differences in the measurement of the exchange of help in the two countries: (1) the period over which the transfer of help is considered (two years in Bulgaria and one year in Hungary); (2) the origin or destination of help (in the Hungarian case members of the respondent's household are excluded where household work and other support is considered); (3) in terms of measurement (number of persons in the Bulgarian and the type of help in the Hungarian survey); (4) in Bulgaria both actual and potential help are measured, while in Hungary only help actually received is measured. 


\section{Results}

Tables 1 and 2 present the model results for the two countries in terms of odds ratios (the reference category for each variable is denoted by 1). The tables reflect significant differences in the outcomes of the four models.

We first discuss the effect of age. In both countries respondents aged 30-34 reveal a lower desire to ever have a first child as compared to younger women, and so do they in Bulgaria where intentions for having a second child are considered. Where timing is considered the inverse observation can be made: women aged 30-34 who intend to ever have a first or a second child are more likely to intend to have a child within the next two years as compared with the younger women. Our data cannot be used to distinguish whether intentions change with age or whether the results are due to a selection effect. However, it can be speculated that a relatively advanced age can be an important reason for wanting to realise the intention without any further postponement.

We discuss in more detail the outcome of the four models separately, each controlled for age, and in the context of the two countries.

The first model reflects intentions to ever become a parent, or inversely, the choice of childlessness. In this model very few variables are statistically significant, probably due to the small number of respondents who intend to stay childless. A sample size of about 1500 respondents (as shown in the Appendix table) may appear to be small for the application of this model.

We find that in both countries women who declare that work is more important than children, are more likely to intend to remain childless. This is the only common statistically significant variable in the two countries. Higher household income associates with higher desires to become a parent in both countries, although statistical significance is observed in Hungary only. Religious respondents in Hungary are more likely to intend to become parents as compared to non-religious respondents, while women with lower education are less likely to intend to become mothers. Marital status has an inverse effect in the two countries. Women in Hungary who do not live with a partner are more likely to prefer voluntary childlessness, while in Bulgaria they are more likely to prefer parenthood. The former association may hold insofar as it can be supposed that women who do not want to have a family are likely not to live with a partner. The latter association requires a more in-depth study.

The second model reflects on the intention to become a mother within two years or later. Here the number of statistically significant variables is considerably larger. In this model we notice several commonalities between the two countries. For what concerns marital status, married women are more likely to time an intended first birth earlier than women not living with a partner. A higher number of siblings is associated with an intention to become a mother earlier. 
Table 1: Odds ratios for intentions to ever become a mother, and intentions to become a mother within 2 years

\begin{tabular}{|c|c|c|c|c|}
\hline \multirow[t]{2}{*}{ Variables } & \multicolumn{2}{|c|}{ Ever } & \multicolumn{2}{|c|}{ In 2 years } \\
\hline & Bulgaria & Hungary & Bulgaria & Hungary \\
\hline Age: $18-24$ & $2.36^{* *}$ & $2.67 * *$ & $0.67 * *$ & $0.14 * * *$ \\
\hline $25-29$ & $2.96 * * *$ & $1.89 *$ & 1.37 & $0.47 * * *$ \\
\hline $30-34$ & 1 & 1 & 1 & 1 \\
\hline Marital status: & & & & \\
\hline Not living with a partner & $1.96^{*}$ & $0.39 *$ & $0.24 * * *$ & $0.15^{* * *}$ \\
\hline Married & 1 & 1 & 1 & 1 \\
\hline Cohabiting & 1.24 & 0.76 & 1.40 & $0.44 * * *$ \\
\hline $\begin{array}{l}\text { Siblings: } \\
\text { None }\end{array}$ & 1 & 1 & 1 & 1 \\
\hline One & 0.94 & 1.40 & $1.41 *$ & $2.49 * * *$ \\
\hline Two or more & 0.99 & 1.07 & $1.67 * *$ & $3.29 * * *$ \\
\hline $\begin{array}{l}\text { Education: } \\
\text { Lower }\end{array}$ & 1.35 & $0.53 *$ & $1.58 * *$ & 1.10 \\
\hline Secondary & 1 & 1 & 1 & 1 \\
\hline Higher & 1.53 & 1.18 & 1.24 & 1.05 \\
\hline $\begin{array}{l}\text { Satisfaction with accommodation } \\
\text { (increasing) }\end{array}$ & 1.17 & 0.99 & $0.76^{*}$ & 0.99 \\
\hline Labour market position: & & & & \\
\hline Does not work nor study & 1.20 & 1.16 & $0.47 * * *$ & 1.20 \\
\hline Studies, does not work & 1.59 & 1.50 & $0.41 * * *$ & $0.25 * * *$ \\
\hline Works in a state firm & 1 & 1 & 1 & 1 \\
\hline Works in a private/mixed firm & 1.68 & 1.13 & $0.67 *$ & 0.71 \\
\hline Equivalent income in the households: & & & & \\
\hline 1st quartile & 1 & 1 & 1 & 1 \\
\hline 2nd quartile & 0.87 & 1.52 & 0.85 & 1.40 \\
\hline 3rd quartile & 1.09 & $2.17 * *$ & 0.78 & 1.14 \\
\hline 4th quartile & 1.49 & 1.83 & $0.60 * *$ & 0.91 \\
\hline Religious & 1 & 1 & 1 & 1 \\
\hline Non-religious & 1.05 & $0.52 * * *$ & 0.91 & 1.08 \\
\hline Parents should have a life of their own: & & & & \\
\hline Disagree & 1 & 1 & 1 & 1 \\
\hline Neither agree nor disagree & 0.63 & 0.63 & 1.17 & 1.02 \\
\hline Agree & 0.94 & 1.16 & $1.44 * *$ & $0.71 *$ \\
\hline $\begin{array}{l}\text { Work more important than having } \\
\text { children: }\end{array}$ & & & & \\
\hline Disagree & 1 & 1 & 1 & 1 \\
\hline Neither agree nor disagree & 0.68 & 0.77 & 0.88 & $0.60 * *$ \\
\hline Agree & $0.59 *$ & $0.38^{* * *}$ & $0.61 * *$ & $0.67 * *$ \\
\hline Psych. well-being (increasing) & 1.26 & 0.96 & $1.15^{*}$ & 1.07 \\
\hline Disorientation (decreasing) & 1.01 & 1.03 & $0.80 * *$ & 0.97 \\
\hline Exchange of help (increasing) & 1.51 & 1.05 & $1.27 * *$ & 1.02 \\
\hline
\end{tabular}

$* * * \mathrm{p}<0.01 ; * * \mathrm{p}<0.05 * \mathrm{p}<0.1$

(\#) Small number of observations 
Table 2: Odds ratios for intentions to ever have a second child, and intentions to have the second child within 2 years

\begin{tabular}{|c|c|c|c|c|}
\hline \multirow[t]{2}{*}{ Variables } & \multicolumn{2}{|c|}{ Ever } & \multicolumn{2}{|c|}{ In two years } \\
\hline & Bulgaria & Hungary & Bulgaria & Hungary \\
\hline Age: $18-24$ & $1.54^{* *}$ & 0.70 & $0.64 *$ & $0.37^{* *}$ \\
\hline $25-29$ & $1.70 * * *$ & 1.19 & $0.66^{*}$ & 0.63 \\
\hline $30-34$ & 1 & 1 & 1 & 1 \\
\hline Marital status: & & & & \\
\hline Not living with a partner & 1.09 & 0.95 & $0.35^{* * *}$ & $0.18^{* * *}$ \\
\hline Married & 1 & 1 & 1 & 1 \\
\hline Cohabiting & 1.09 & $0.72 *$ & 1.43 & $0.43 * *$ \\
\hline Siblings: & & & & \\
\hline None & 1 & 1 & 1 & 1 \\
\hline One & 1.28 & 1.05 & 0.90 & 0.67 \\
\hline \begin{tabular}{|l} 
Two or more \\
\end{tabular} & $1.76^{* *}$ & 1.34 & 0.84 & 0.97 \\
\hline Age of 1st child (increasing): & $0.87 * * *$ & $0.85^{* * *}$ & $1.14 * * *$ & $1.16^{* * *}$ \\
\hline Education: & & & & \\
\hline Lower & 0.89 & 1.28 & $1.52 *$ & 0.84 \\
\hline Secondary & 1 & 1 & 1 & 1 \\
\hline Higher & 1.05 & 1.70 & $1.40^{*}$ & $2.84 * * *$ \\
\hline $\begin{array}{l}\text { Satisfaction with accommodation } \\
\text { (increasing) }\end{array}$ & 0.95 & 1.00 & 0.98 & $0.89 * *$ \\
\hline Labour market position: & & & & \\
\hline Does not work nor study & 1.08 & 0.85 & 1.46 & 0.70 \\
\hline Studies, does not work & 1.56 & 0.92 & 0.93 & 1.44 \\
\hline Works in a state firm & 1 & 1 & 1 & 1 \\
\hline Works in a private/mixed firm & 1.29 & 0.96 & 1.17 & 1.26 \\
\hline Parental leave & 1.43 & 0.99 & 0.71 & 1.43 \\
\hline Equivalent income in the househol & & & & \\
\hline 1st quartile & 1 & 1 & 1 & 1 \\
\hline 2nd quartile & $1.43 * *$ & 0.90 & 0.94 & 0.88 \\
\hline 3rd quartile & 1.31 & 1.08 & 0.78 & 0.63 \\
\hline 4th quartile & $1.71 * * *$ & 1.17 & 0.94 & 1.01 \\
\hline Religious & 1 & 1 & 1 & 1 \\
\hline Non-religious & $0.66^{* * *}$ & $0.48^{* * *}$ & 0.96 & 1.25 \\
\hline Parents should have a life of their & & & & \\
\hline Disagree & 1 & 1 & 1 & 1 \\
\hline Neither agree nor disagree & 0.89 & 1.00 & 0.91 & 0.81 \\
\hline Agree & 1.08 & 1.48 & 0.76 & 1.14 \\
\hline $\begin{array}{l}\text { Work more important than having } \\
\text { children: }\end{array}$ & & & & \\
\hline Disagree & 1 & 1 & 1 & 1 \\
\hline Neither agree nor disagree & $0.71 *$ & 0.86 & 0.77 & 0.90 \\
\hline Agree & $0.64 * * *$ & $0.31 * * *$ & $0.67 * * *$ & $0.45^{* * *}$ \\
\hline Psych. well-being (increasing) & 1.04 & 1.25 & $1.18^{*}$ & 1.07 \\
\hline Disorientation (decreasing) & $1.23 * *$ & $1.49 * *$ & 0.97 & $0.69^{* *}$ \\
\hline Exchange of help (increasing) & $1.28 *$ & $1.21 * *$ & $1.69 * * *$ & 0.93 \\
\hline
\end{tabular}

$* * * \mathrm{p}<0.01 ; * * \mathrm{p}<0.05 * \mathrm{p}<0.1$ 
Labour market status has a mixed influence. As it could be expected, being in education correlates positively with the postponement of the transition to motherhood in both countries. Women in Bulgaria working in a state firm are more likely to intend to have a child earlier as compared with women in any other labour market position considered here. Hence in Bulgaria job security influences the timing of positive intentions for a first child. Unemployed women, included in the category "does not work, nor study", are relatively more likely to postpone the first birth in Bulgaria than in Hungary. This difference can be attributed to more powerful social policies in Hungary.

Several variables were found to be statistically significant only in Bulgaria. Women with lower education are more likely to intend to have a child within two years as compared to women with a completed secondary or higher education. Higher satisfaction with their living accommodations makes women in Bulgaria postpone childbearing. (The same result was achieved by using a variable that measures the size of the dwelling, i.e. an objective instead of a subjective measure.) High-level equivalent income in the household is associated with a higher propensity to postpone the first birth.

In terms of ideational factors, women who declare that work is more important than children are more likely to postpone a desired first birth as compared with women that disagree with this statement. Respondents in Bulgaria who agree more with the statement "parents have a life of their own" are willing to have the first child sooner as compared to those who do not share this attitude, while in Hungary the inverse relation is seen. This contradictory effect needs further attention.

The impact of personal perception of anomie is revealed through both variables used for its measurement: respondents with better psychological well-being are less likely to postpone the birth of the first child, while those with a lower level of disorientation are more likely to do so (we come back to the latter observation in the discussion of the model for the timing of intentions for a second birth). Also social capital matters: the higher the exchange of help, the less likely is a postponement of the first birth.

The third model refers to the intentions of ever having a second child. Among the demographic variables we find a conspicuous effect for the age of the first child: the higher this age the less likely is the intention to have a second child. Religiosity is another statistically significant variable in both countries: less religious women are less likely to intend to have a second child. The number of siblings was found significant in Bulgaria; cohabiting women in Hungary are less likely to intend to have a second child than married women.

Household income is important only in Bulgaria: the higher this income, the more likely is the desire to have a second child. We recall from the description of the variables that households with two children have a considerably lower household income than those with one child: this difference appears significant in Bulgaria and not in Hungary. 
We observe again the significance of the preference of work relative to having children. Anomie and social capital matter here, too. Decreasing disorientation favours higher desires to have a second child, and so does a higher level of exchange of help.

The fourth model helps to analyse the timing of a positive intention to have a second child. Only two variables have a common effect in both countries: preference of work to having children and age of the first child. Several variables have a differential effect. Thus women living without a partner are likely to postpone the birth of a second child as compared to married women; the same is observed for cohabiting women in Hungary but not in Bulgaria. In both countries women with higher education are likely to have their second child earlier rather than later as compared to women with secondary education; this association is likely to be observed when the birth has been postponed until the completion of the higher education. In Bulgaria women with lower education are also more likely not to postpone the birth.

Satisfaction with the living accommodations in Hungary relates inversely to the timing of the second birth: women who are more satisfied with their living conditions are more likely to postpone the birth, as was the case in Bulgaria with first births. (Like in Bulgaria, this result was also achieved when using an alternative variable: size of the dwelling measured in square meters.) We can speculate that an increase in the household size through a birth is expected to worsen the living conditions.

Anomie has an effect on timing of intentions for a second birth. Better psychological well-being associates with earlier intended timing of the second birth in Bulgaria. Disorientation does not have a statistically significant effect in Bulgaria, but lower disorientation among Hungarian women who intend to have a second child is linked to a postponement of the wanted birth. A similar result was observed in Bulgaria when timing of the first child is considered. It is beyond the scope of this paper to review the relevant theoretical considerations; however, we could speculate that in accordance with Merton's theory of anomie, some people react to anomic situations by sticking closer to traditional norms and goals in order to decrease their uncertainty (see also Friedman et al., 1994). For what concerns social capital, a higher level of help exchange in Bulgaria relates to the preference to have the child within two years.

\section{Concluding remarks}

In this paper we had two principal aims. First, we embedded the study of fertility intentions within the current debate on very low fertility, where postponement of fertility is a key issue. For the purpose we study intentions to ever have a first or a second child and further divide the positive intentions to have a child into intentions to have this child within the next two years or later. The study is based on the use of questions that are often available in largescale prospective surveys on fertility. Second, we focused on fertility decision-making in the 
context of two countries in transition characterised by very low fertility: Bulgaria and Hungary. We argued that, besides the standard argumentation for economic factors and ideational change as shaping choices concerning fertility in such societies, anomie and social capital play a crucial role as well.

For what concerns the first methodological point, we showed that it is remarkably instructive to analyse fertility intentions separately by birth order and using the "ever vs. never" and "now vs. later" dichotomies. The explanatory variables can have a specific association with either type of intentions. We thus get enriched information on the decisionmaking process as depicted by the determinants of intentions. In the case of our study we find that one ideational variable has an impact in all cases, i.e. for both "ever" and "now or later" and for both births orders: the preference between work and having children. Women that find work more important than having children are less likely to intend having children, and if this intention is positive, are more likely to postpone the birth. Some variables have only a timingspecific effect on fertility intentions, such as satisfaction with the dwelling, while others, like religiousness, have a pronounced effect only on the 'ever' intentions. Other variables effect both aspects of fertility intentions, although their effect can be in the same or in a different direction of association. Inferences of this type can be useful for the better understanding of the construction of fertility intentions. Furthermore, they will be of use in building adequate family policies that aim towards an increase in fertility. Recently Lutz and Skirbekk (2004) suggested the implementation of "tempo policies" that aim towards earlier timing of births, distinguished from traditional "quantum" pronatalistic policies aimed towards a higher number of births. Differentiation of fertility intentions as suggested in this paper can be helpful for the tempo- and quantum differentiation of relevant fertility policies.

For what concerns the second point, anomie and social capital are among the significant factors in both Bulgaria and Hungary, when controlling for other factors that are usually taken into account in analyses of fertility decision-making. Our analyses indicate that the societal transformation, encompassing shifts in values, persistence of anomie, and changes in the social and economic situation of women, exercises a similar effect on level and timing of fertility intentions in both countries; some differences are outlined in the economic circumstances which seem to be more effective in Bulgaria. Although we claim that anomie and factors related to social capital are especially important in countries experiencing rapid societal changes, there is no reason yet to reject their importance in shaping fertility decisions in other societies. 


\section{References:}

Ajzen, Icek. 1991. The theory of planned behaviour, Organizational Behaviour and Human Decision Processes, Vol. 50, pp.179-211.

Andorka, Rudolf. 1994. Social changes and social problems in Hungary since the 1930s: Economic, social and political causes of the collapse of the socialist system. Comparative Social Research, Vol. 14, pp.49-96.

Arroyo, Cristino and Junsen Zhang. 1997. Dynamic microeconomic models of fertility choice: A survey. Journal of Population Economics, 10:23-65.

Arts W., P. Hermkens, P. Van Wijck (1995). Anomie, distributive justice and dissatisfaction with material well-being in Eastern Europe. International Journal of Comparative Sociology 36,1-2: 1-16.

Astone, Nan Marie; Constance Nathanson, Robert Schoen, Young Kim. 1999. Family Demography, Social Theory, and Investment in Social Capital. Population and Development Review, 25(1):1-32.

Becker, Gary. 1990. A Treatise on the Family. Harvard University Press.

Bhaumik, Sumon. 2002. Does Economic Uncertainty Have an Impact on Decisions to Bear Children? Evidence from Eastern Germany. Working Paper WP-2002-037, MaxPlanck Institute for Demographic Research.

Billari, Francesco C. and Dimiter Philipov. 2004. Women's education and entry into a first union: A simultaneous-hazard comparative analysis of Central and Eastern Europe. Vienna Yearbook of Population Research, 91-110.

Buehler, C. and D. Philipov. 2005. Foundations of fertility-related social capital: theoretical considerations and empirical results for Bulgaria. Unpublished manuscript. Available also as: Zur Bedeutung sozialen Kapitals für Fertilitätsentscheidungen (Theoretische Überlegungen und empirische Darstellungen am Beispliel Bulgariens). WP 2004-024, Max-Planck Institute for Demographic Research, Rostock, Germany.

Council of Europe. 2003. Recent Demographic Developments in Europe, Council of Europe, Strasbourg.

Davie, G. 1994. Religion in Britain since 1945: Believing without Belonging. Oxford: Blackwell.

Dharmalingam, A. and S. Philip Morgan. 2004. Pervasive Muslim-Hindu Fertility Differences in India. Demography, 41/3.

Durkheim, E. 1964. The division of Labour in Society. New York, The Free Press.

Durkheim, E. 1966. Suicide. New York, The Free Press.

Ermisch J.F. 2003. An Economic Analysis of the Family. Princeton and Oxford: Princeton University Press.

Friedman, Debra and Hechter, Michael and Kanazawa, Satoshi. 1994. A Theory of the Value of Children. Demography 31(3): 375-401

Gustafsson, Siv. 2001. Optimal age at motherhood. Theoretical and empirical considerations on postponement of maternity in Europe, Journal of Population Economics, 14, 2: 225-247. 
Habich R. and Z. Spéder, 1998. Winners and Losers: Transformational outcome in a comparative context. In: T Kolosi, I.-G. Tóth, G. Vukovich (editors) Social Report 1998, Tárki - Social Research Informatics Center, pp. 123-147.

Hobcraft, J. and K. Kiernan. 1995. Becoming a parent in Europe. In European Population Conference, EAPS-IUSSP Vol. 1. Milano: Franco Angeli.

Hotz, V.Joseph; Jacob Alex Klerman; Robert J. Willis. 1997. The Economics of Fertility in Developed Countries: A Survey. Chapter 7 in: Handbook of Population and Family Economics, Vol. A., Elsevier, pp.275-347.

Huber, Stefan. 2003. Zetralität und Inhalt. Ein neues multidimensionales Messmodell der Religiosität. Leske und Budrich. Opladen

Kamarás, Ferenz and Klára Szukics. 2003. Ten Years after the Wedding (A longitudinal survey of marriages contracted in 1990 and 1991). Central Statistical Office, Budapest.

Kohler, Hans-Peter; F.C. Billari, H.-A. Ortega. 2002. The Emergence of Lowest-Low Fertility in Europe During the 1990s. Population and Development Review, Vol 28/4, pp. 641680.

Kopp, M., Á. Skrabski, J. Löke, S. Szedmák, 1999: The Hungarian State of Mind in a Transforming Society. In. Spéder, ed. Hungary in Flux. Society, Politics and Transformation. Hamburg: Kraemer, p. 135-150.

Kotowska, E., editor. 2000. Demographic change in Poland during the 90s in the light of the second demographic transition (in Polish). Szkola Glowna Handlowa w Warszawie.

Kotowska, Irena E. and J. Jozwiak, editors. 2003. Population of Central and Eastern Europe: Challenges and Opportunities. Statistical Publishing Establishment, Warsaw.

Lutz, Wolfgang and Vegard Skirbekk. 2004. How Would "Tempo Policies" Work? Exploring the Effect of School Reforms on Period Fertility in Europe. European Demographic Research Papers N2, Vienna Institute of Demography.

Maslow. 1954. Motivation and Personality. Harper, New York.

Merton, Robert. 1966. Social theory and social structure. Free press, New York.

Miller W.B., Pasta D.J. 1994. "The Psychology of Child Timing: A Measurement Instrument and a Model", Journal of Applied Social Psychology: 24, 218-250.

Miller W.B., Pasta D.J. 1995. "Behavioural Intentions: Which Ones Predict Fertility Behaviour in Married Couples?", Journal of Applied Social Psychology: 25, 530-555.

Morgan S.-Philip. 2003. Is Low Fertility a Twenty-First Century Demographic Crisis? Demography, Vol. 40/4, pp. 589-604.

Philipov, Dimiter. 2003. Fertility in times of discontinuous societal change. In: Kotowska and Jozwiak (eds.), pp. 665-690.

Philipov D. and Dorbritz, J. 2003. Demographic consequences of economic transition in countries of central and eastern Europe. Council of Europe Publishing.

Philipov, Dimiter and H.-P. Kohler. 2001. Tempo effects in the fertility decline in Eastern Europe: evidence from Bulgaria, the Czech Republic, Hungary, Poland, and Russia, European Journal of Population, 17/1, 36-60.

Philipov, Dimiter and V. Shkolnikov. 2001. Fertility intentions and social capital-based coping strategies: results from the Russian longitudinal monitoring survey. Paper presented at the 2001 Meeting of the Population Association of America, Washington D.C. 
Quesnel-Vallée, Amélie and S.P. Morgan. 2003. Missing the Target? Correspondence of Fertility Intentions and Behavior in the U.S., Population Research and Policy Review, 22/5-6, 497-525.

Rabušic, L. and P. Mareš. 1996. Is Czech Society Anomic?, Sociologický časopis, XXXII:2, 175-187 (in Czech).

Ranjan, Priya. 1999. Fertility Behaviour under Income Uncertainty, European Journal of Population, Vol.15,pp. 25-43.

Schoen, Robert; Young Kim, Constance Nathanson, Jason Fields, Nan Marie Astone. 1997. Why Do Americans Want Children? Population and Development Revew, 23(2):333358.

Sobotka, Tomas. 2003a. Understanding lower and later fertility in Central and Eastern Europe. In: Kotowska and Jozwiak (eds.), pp. 691- 724.

Sobotka, Tomas. 2003b. Re-Emerging Diversity: Rapid Fertility Changes in Central and Eastern Europe After the Collapse of the Communist Regimes. Population: English Edition, Vol. 58/4-5, pp. 451-486.

Spéder, Zsolt; B. Paksi; Zs. Elekes. 1999. Anomy and Satisfaction at the Beginning of the Nineties. In: T Kolosi, I.-G. Tóth, G. Vukovich (editors) Social Report 1998, Tárki Social Research Informatics Center, pp. 483-505.

Spéder, Zsolt. 2002. Fertility and Structural Change in Hungary. Working paper 4, Demographic Research Institute, Central Statistical Office.

Spéder, Zsolt; Zs. Elekes; I.Harcsa; P. Róbert. 2002. Hungary: The Outlines of the Trasformation. In: W.Adamski, P. Machonin, and W.Zapf(eds.), Structural Change and Modernisation in Post-Socialist Societies. Hamburg: Karemer, pp. 79-154.

Srole L. 1956. Social Integration and Certain Corollaries: An Exploratory Study. American Sociological Review, 21:709-716.

Stark, R., E. Hamberg and A. Miller. 2005. Exploring Spirituality and Unchurched Religions in America, Sweden, and Japan. Journal of Contemporary Religion, Vol. 20, n. 1, pp. $3-23$

StataCorp, 2003. Stata Statistical Software: Release 8.0. College Station, TX: Stata Corporation.

United Nations. 2002. New forms of household formation in Central and Eastern Europe: Are they related to newly emerging value orientations? Chapter 6 in Part 3: "Social Dimensions of Economic Development" in: Economic Survey of Europe, N.1, UN ECE, Geneva.

Van de Venn, W.P.M.M. and B.M.S. Van Pragg, 1981. The demand for deductibles in private health insurance: A probit model with sample selection. Journal of Econometrics, 17: 229-252.

Weinstein, Neil. 1980. Unrealistic Optimism About Future Life Events. Journal of Personality and Social Psychology, Vol. 39, No. 5, pp.806-820.

Williams L., Abma J., Piccinino L.J. 1999. "The Correspondence Between Intention To Avoid Childbearing and Subsequent Fertility: A Prospective Analysis", Family Planning Perspectives: 31, 220-227. 


\section{Appendix: descriptive data}

The table in the Appendix informs about the variables and the number of observations in each model. 1,464 women in Bulgaria have no children, and only $4.7 \%$ of them intend to stay childless. This leaves 1,399 women who intend to have a child either within the next 2 years or later. In Hungary the corresponding numbers are 1,441, 5.6\%, and 1,360. In both countries the level of voluntary childlessness is thus very low. Further on, the table shows that 1,384 women in Bulgaria have one child and 861 of them want to have a second child; in Hungary the numbers are 513 and 377, respectively.

Appendix table: Descriptive data for Bulgaria $(\mathrm{Bg})$ and Hungary $(\mathrm{H})$, females aged 18-34, in per cent ${ }^{(*)}$

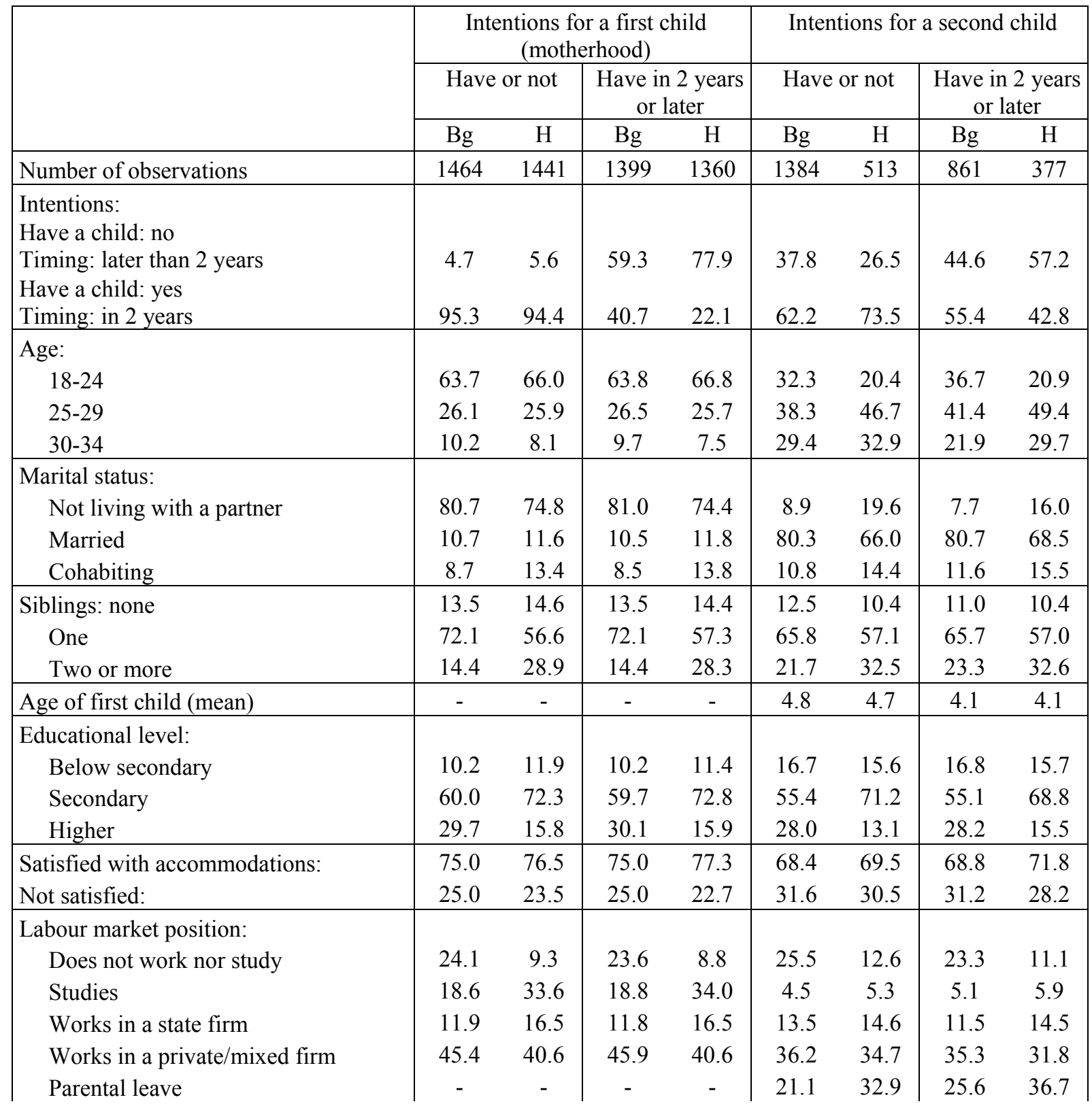




\begin{tabular}{|c|c|c|c|c|c|c|c|c|c|}
\hline Equivalent income in the households: & 1st quartile & 16.7 & 10.9 & 16.5 & 10.5 & 28.5 & 22.3 & 26.4 & 21.0 \\
\hline \multicolumn{2}{|l|}{ 2nd quartile } & 21.4 & 17.6 & 21.1 & 17.5 & 25.5 & 31.6 & 27.0 & 30.6 \\
\hline \multicolumn{2}{|l|}{ 3rd quartile } & 24.1 & 29.1 & 24.0 & 29.4 & 24.3 & 22.4 & 23.8 & 22.2 \\
\hline \multicolumn{2}{|l|}{ 4th quartile } & 37.8 & 42.4 & 38.4 & 42.6 & 21.8 & 23.7 & 22.8 & 26.2 \\
\hline \multicolumn{10}{|l|}{ Religiosity: } \\
\hline \multicolumn{2}{|c|}{ Religious person } & 63.1 & 67.5 & 63.1 & 68.8 & 62.2 & 67.7 & 65.1 & 72.0 \\
\hline \multicolumn{2}{|c|}{ Non-religious person } & 36.9 & 32.5 & 36.9 & 31.2 & 37.8 & 32.3 & 34.9 & 28.0 \\
\hline \multicolumn{2}{|c|}{$\begin{array}{l}\text { Parents should have a life of their own: } \\
\text { Agree }\end{array}$} & 50.2 & 65.3 & 50.3 & 65.6 & 54.6 & 64.7 & 54.4 & 66.3 \\
\hline \multicolumn{2}{|c|}{ Neither agree nor disagree } & 26.1 & 13.0 & 25.7 & 12.5 & 24.6 & 11.5 & 24.0 & 10.6 \\
\hline \multicolumn{2}{|c|}{ Disagree } & 23.8 & 21.6 & 24.0 & 21.9 & 20.8 & 23.8 & 21.6 & 23.1 \\
\hline \multicolumn{10}{|c|}{ Work more important than having children: } \\
\hline \multicolumn{2}{|c|}{ Agree } & 31.1 & 30.7 & 31.3 & 29.6 & 39.2 & 25.6 & 42.3 & 20.1 \\
\hline \multicolumn{2}{|c|}{ Neither agree nor disagree } & 12.7 & 16.9 & 12.6 & 16.9 & 13.5 & 13.3 & 12.7 & 13.8 \\
\hline \multicolumn{2}{|c|}{ Disagree } & 56.2 & 52.3 & 56.1 & 53.5 & 47.3 & 61.1 & 45.0 & 66.1 \\
\hline \multicolumn{10}{|c|}{ Psychological well-being: } \\
\hline \multirow[t]{3}{*}{ 1. Loneliness } & - rather yes & 22.4 & 23.3 & 21.7 & 23.2 & 18.6 & 23.0 & 17.6 & 20.0 \\
\hline & - neither/nor & 10.7 & - & 10.6 & - & 10.7 & - & 10.5 & - \\
\hline & - rather not & 66.9 & 72.7 & 67.7 & 72.8 & 70.6 & 77.0 & 71.9 & 80.0 \\
\hline \multirow[t]{3}{*}{ 2. Unhappiness } & - rather yes & 18.1 & 19.3 & 17.7 & 19.0 & 15.4 & 23.4 & 14.0 & 18.3 \\
\hline & - neither/nor & 9.6 & - & 9.7 & - & 10.7 & - & 10.6 & - \\
\hline & - rather not & 72.3 & 80.7 & 72.7 & 81.0 & 73.9 & 76.6 & 75.4 & 81.7 \\
\hline \multicolumn{10}{|c|}{ Disorientation: } \\
\hline & - rather yes & 35.4 & 63.1 & 35.2 & 62.8 & 42.7 & 58.7 & 41.6 & 60.6 \\
\hline & - neither/nor & 29.6 & - & 29.5 & - & 28.0 & - & 27.3 & - \\
\hline & - rather not & 35.0 & 36.9 & 35.3 & 37.2 & 29.4 & 41.3 & 31.1 & 39.4 \\
\hline \multicolumn{10}{|c|}{ 2. Life is too complicated } \\
\hline & - rather yes & 55.6 & 64.2 & 55.3 & 64.3 & 60.3 & 53.5 & 57.1 & 56.6 \\
\hline & - neither/nor & 21.1 & - & 21.2 & - & 21.5 & - & 22.5 & - \\
\hline & - rather not & 23.3 & 35.8 & 23.5 & 35.7 & 18.2 & 46.5 & 20.4 & 43.4 \\
\hline \multicolumn{10}{|c|}{ 3. No one cares what happens to other people } \\
\hline & - rather yes & 55.6 & 51.8 & 55.3 & 52.5 & 60.3 & 42.6 & 57.1 & 45.0 \\
\hline & - neither/nor & 21.1 & - & 21.2 & - & 21.5 & - & 22.5 & - \\
\hline & - rather not & 23.3 & 48.2 & 23.5 & 47.5 & 18.2 & 57.4 & 20.4 & 55.0 \\
\hline \multicolumn{10}{|l|}{ Help received: } \\
\hline \multicolumn{2}{|l|}{ No } & 5.1 & 45.8 & 5.0 & 45.3 & 10.1 & 23.6 & 8.2 & 21.6 \\
\hline Yes & & 94.9 & 54.2 & 95.0 & 54.7 & 89.9 & 76.4 & 91.8 & 78.4 \\
\hline Help given: & & & & & & & & & \\
\hline No & & 13.4 & 48.2 & 12.8 & 48.1 & 17.3 & 43.3 & 15.6 & 39.6 \\
\hline Yes & & 86.6 & 51.8 & 87.2 & 51.9 & 82.7 & 56.7 & 84.4 & 60.4 \\
\hline
\end{tabular}

$(*)$ Where the sum of the percents is not equal to 100.0 , they do not include missing values, refusals, "don't know", or there is a rounding effect. Some variables are not fully compatible between the two countries; see explanations in the text. 


\section{VIENNA INSTITUTE OF DEMOGRAPHY}

\section{Working Papers}

Franz Schwarz. Widening Educational Inequalities in Mortality: An Analysis for Austria with International Comparisons. VID Working Papers 07/2005. Vienna: Vienna Institute of Demography.

Kim, Jungho, Henriette Engelhardt, Alexia Prskawetz, and Arnstein Aassve. Does Fertility Decrease the Welfare of Households? An Analysis of Poverty Dynamics and Fertility in Indonesia. VID Working Papers 06/2005. Vienna: Vienna Institute of Demography.

Kim, Jungho. Women's Education in the Fertility Transition: The Reversal of the Relationship Between Women's Education and Birth Spacing in Indonesia. VID Working Papers 05/2005. Vienna: Vienna Institute of Demography.

Kim, Jungho. Learning by Doing and Learning from Others in Contraceptive Technology. VID Working Papers 04/2005. Vienna: Vienna Institute of Demography.

Heiland, Frank, Alexia Prskawetz, and Warren C. Sanderson. Do the MoreEducated Prefere Smaller Families? VID Working Papers 03/2005. Vienna: Vienna Institute of Demography.

Henriette Engelhardt und Alexia Prskawetz. Arbeitsmarkt und Demographie. VID Working Papers 02/2005. Vienna: Vienna Institute of Demography.

Sobotka, Tomáš, Maria Winkler-Dworak, Maria Rita Testa, Wolfgang Lutz, Dimiter Philipov, Henriette Engelhardt, and Richard Gisser. Monthly Estimates of the Quantum of Fertility: Towards a Fertility Monitoring System in Austria. VID Working Papers 01/2005. Vienna: Vienna Institute of Demography.

Schwarz, Franz. 2004. Analysis of Inequalities in Waiting Time at the Visit to the Physician using Regression Modeling for Duration Data. VID Working Papers 04/2004. Vienna: Vienna Institute of Demography.

Prskawetz, Alexia, Tomas Kögel, Warren C. Sanderson, and Sergei Scherbov. 2004. The Effects of Age Structure on Economic Growth: An Application of Probabilistic Forecasting to India. VID Working Papers 03/2004. Vienna: Vienna Institute of Demography. 